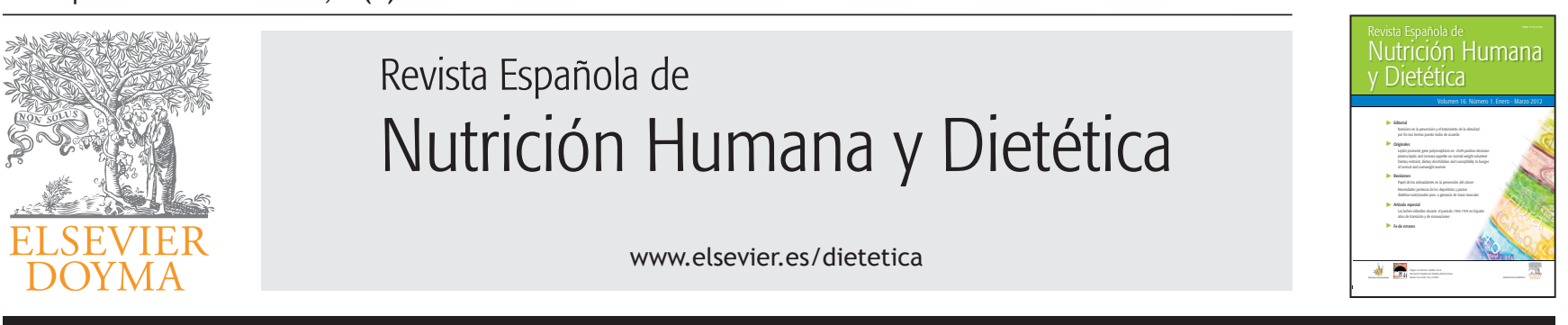

REVISIÓN

\title{
Papel de los antioxidantes en la prevención del cáncer
}

\author{
Laura Llacuna ${ }^{\mathrm{a}, *}$ y Nuria Mach ${ }^{\mathrm{a}, \mathrm{b}}$ \\ aEstudis de Ciències de la Salut, Universitat Oberta de Catalunya (UOC), Barcelona, España \\ ${ }^{\mathrm{b}}$ Animal Breeding and Genomics Centre, Wageningen UR Livestock Research, Lelystad, Países Bajos
}

Recibido el 3 de mayo de 2011; aceptado el 8 de noviembre de 2011

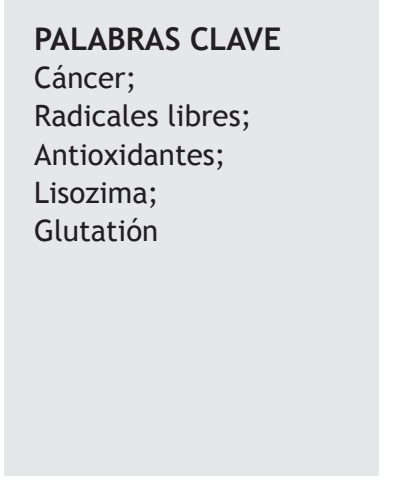

\section{PALABRAS CLAVE}

Cáncer

Radicales libres;

Glutatión

\section{KEYWORDS}

Cancer;

Free radicals;

Antioxidant;

Lysozyme;

Glutathione
Resumen La naturaleza de la asociación entre radicales libres y cáncer es compleja y paradójica. Parece que los radicales libres y el estrés oxidativo pueden inducir cáncer, pero al mismo tiempo las células transformadas, es decir, las células cancerosas, generan más radicales libres que las células normales. Compuestos endógenos antioxidantes, entre ellos el glutatión y la lisozima, pueden limitar los efectos del estrés oxidativo; sin embargo, dichos sistemas pueden ser rápidamente acaparados por elevadas cantidades de radicales libres. De ahí la importancia de incrementar la concentración de antioxidantes de la célula para prevenir posibles agentes adversos que podrían llegar a originar un proceso canceroso. Una buena alimentación, así como conocer y emplear alimentos con propiedades antioxidantes, puede ser de gran ayuda para la prevención del cáncer.

(C) 2011 Asociación Española de Dietistas-Nutricionistas. Publicado por Elsevier España, S.L. Todos los derechos reservados.

\section{Role of antioxidants in the prevention of cancer}

Abstract The nature of the association between free radicals and cancer is complex and paradoxical, as it seems that free radicals and oxidative stress can induce cancer, but at the same time the transformed cells, that is, the cancer cells generate more free radicals than normal cells. Endogenous antioxidant compounds, including glutathione and lysozyme, can limit the effects of oxidative stress, but these systems can be quickly saturated by high amounts of free radicals. It is important to increase the cellular levels of antioxidants that could provide protection against possible adverse agents that can cause a cell cancer. A good diet and the knowledge of several compounds of foods with antioxidant effects may be helpful to prevent cancer disease.

○ 2011 Asociación Española de Dietistas-Nutricionistas. Published by Elsevier España, S.L. All rights reserved.

\footnotetext{
*Autor para correspondencia.

Correo electrónico: laurallacuna@hotmail.com (L. Llacuna).
} 


\section{Introducción}

Cáncer es el término que se emplea para un grupo de enfermedades que tienen un denominador común: la transformación de la célula normal en otra que se comporta de manera muy peligrosa para el cuerpo humano. Una célula normal se convierte en una célula cancerosa debido a un cambio o mutación en el ADN. A veces esas células, cuya carga genética ha cambiado, mueren o son eliminadas en los ganglios linfáticos. Sin embargo, otras veces siguen con vida y se reproducen ${ }^{1}$. Las células cancerosas tienen un aspecto diferente, bien porque su forma ha cambiado, bien porque contienen núcleos más grandes o más pequeños ${ }^{2}$. Dichas células son incapaces de realizar las funciones que corresponden a las células pertenecientes a ese tejido ${ }^{2}$. Generalmente se multiplican muy rápidamente, porque les falta un mecanismo de control del crecimiento ${ }^{3}$. Con frecuencia, son inmaduras debido a que se multiplican muy rápidamente y no tienen tiempo suficiente para crecer plenamente antes de dividirse.

Al formarse un gran número de células cancerosas, se amontonan, presionan o bloquean otros órganos y les impiden realizar su trabajo ${ }^{3}$. Como no se limitan al espacio originario donde se forman y se extienden a otras zonas, se dice que son invasivas ${ }^{4}$.

Un antioxidante es una molécula capaz de retardar o prevenir la oxidación de otras moléculas ${ }^{5}$. La oxidación es una reacción química de transferencia de electrones de una sustancia a un agente oxidante. Las reacciones de oxidación pueden producir radicales libres que comienzan reacciones en cadena que dañan las células. Los antioxidantes terminan estas reacciones quitando intermedios del radical libre e inhiben otras reacciones de oxidación oxidándose ellos mismos $^{5}$. Los antioxidantes son sustancias que pueden proteger a la célula contra el daño causado por las moléculas inestables conocidas como radicales libres ${ }^{5}$.

Los radicales libres son átomos con un electrón célibe en su órbita externa, lo que les imprime una marcada inestabilidad y una gran reactividad que los hace muy tóxicos y muy oxidantes, capaces de dañar de manera indiscriminada estructuras biológicas de las células por reacción en cadena de peroxidación. Los radicales libres recorren nuestro organismo intentando captar un electrón de las moléculas estables, con el fin de lograr su estabilidad electroquímica y con potenciales reacciones en cadenas destructoras de nuestras células ${ }^{6}$. Cuando los sistemas enzimáticos defensivos son desbordados por una mayor producción de radicales libres determinada por factores externos, se genera especialmente $\mathrm{OH}^{\prime}$, que tiene una muy alta actividad oxidante y contra el cual no existe ningún mecanismo natural o enzimático de defensa. Estos elementos van acumulando lentamente lesiones en sistemas biológicos celulares ${ }^{7}$ : proteínas, fosfolípidos de la membrana celular, ácidos nucleicos $(A D N)^{8}$, lipoproteínas de baja densidad o colesterol ${ }^{9}$, enzimas con grupos sulfhidrilos (lisozima) o mitocondrias. Aunque las reacciones de oxidación son cruciales para la vida, también pueden ser perjudiciales. Tanto las plantas como los animales mantienen complejos sistemas con múltiples tipos de antioxidantes, tales como el glutatión, las vitaminas $\mathrm{C}$ y E, así como enzimas tales como la catalasa, la superóxido dismutasa y varias peroxidasas. Bajas concentraciones de antioxidantes o la inhibición de las enzimas antioxidantes causan estrés oxidativo y pueden dañar o producir la apoptosis de las células ${ }^{10}$. El estrés oxidativo se ha asociado a la patogenia de muchas enfermedades humanas, por lo que el uso de antioxidantes en farmacología se estudia intensivamente, sobre todo como tratamiento de accidentes cerebrovasculares y enfermedades neurodegenerativas ${ }^{11}$. El estrés oxidativo resulta de un desequilibro entre prooxidantes y antioxidantes ${ }^{6}$. Las células pueden adaptarse a ciertos incrementos de estrés oxidativo, pero si este resulta agresivo, se produce un desacoplamiento de las funciones celulares y un daño irreversible o la muerte celular ${ }^{4}$. Para evitar la aparición de los radicales libres mediante la alimentación, hay que tener en consideración dos factores: evitar los alimentos que pueden aumentar la aparición de radicales libres y aumentar el consumo de alimentos que aportan sustancias antioaxidantes capaces de reforzar los sistemas de protección del organismo. Resulta imprescindible adoptar una alimentación rica en productos vegetales, capaces de proporcionar los principios que neutralizan sus efectos perniciosos. Cabe destacar que no existe ningún otro alimento como las frutas y las hortalizas que posean tantos antioxidantes que transformen las células en fortalezas contra los radicales libres ${ }^{83}$.

El daño causado por los radicales libres y el estrés oxidativo puede dar lugar a varios tipos de cáncer ${ }^{11}$. No obstante, los antioxidantes como el glutatión y la lisozima pueden interactuar con los radicales libres y estabilizarlos, con lo que evitan parte del daño celular que estos podrían causar y actúan como prevención contra el cáncer ${ }^{10}$. En el presente trabajo de revisión, se describen algunas vías de tumorogénesis generales y moleculares y se describe el efecto beneficioso de los antioxidantes en la prevención y la terapia contra el cáncer.

\section{Relación entre los radicales libres y el cáncer}

La naturaleza de la asociación entre radicales libres y cáncer es compleja y paradójica. Se ha descrito en la literatura científica que los radicales libres y el estrés oxidativo pueden inducir cáncer ${ }^{1}$, pero al mismo tiempo las células transformadas, es decir las células cancerosas, generan más radicales libres que las células normales ${ }^{12}$. El sistema antioxidante de la tiorredoxina está paradójicamente amplificado en las células malignas, así como la estimulación de la progresión del ciclo celular por factores de crecimiento o por mutaciones puede activar el receptor de la tirosincinasa que involucra la generación y el incremento de los radicales libres $^{13}$. Compuestos endógenos antioxidantes como la superóxido dismutasa, la catalasa, el glutatión, los alfatocoferoles y los betacarotenos pueden limitar los efectos del estrés oxidativo, aunque estos sistemas pueden ser rápidamente acaparados por elevadas cantidades de radicales libres ${ }^{14}$. Diversos agentes quimioterapéuticos, como la doxorubicina o la bleomicina, pueden ser selectivamente tóxicos para las células tumorales debido al incremento del estrés oxidativo que empuja a estas células ya estresadas a su límite. 


\section{Inducción del cáncer por los radicales libres}

Los radicales libres se producen como resultado de la oxidación celular. Las principales especies oxidantes incluyen el radical superóxido, el hidroxilo y el peróxido de hidróge$\mathrm{no}^{10}$. Un número limitado y controlado de estos elementos resulta beneficioso para el organismo, por su papel que desempeñan en el organismo dentro del sistema inmunitario, dado que son capaces de eliminar microorganismos patógenos $^{15}$. Cuando el número de radicales libres aumenta y se desestabiliza, produce resultados negativos. Así, por ejemplo, se ha visto la relación que existe entre estas moléculas y ciertas enfermedades de carácter degenerativo, como alteraciones del aparato circulatorio y del sistema nervioso y otras enfermedades como el cáncer, el sida o el envejecimiento precoz $^{16}$. Estos resultados negativos se producen porque los radicales libres alteran el ADN de las células e impiden la renovación celular o alteran su normal funcionamiento ${ }^{17}$. De forma específica, Southern et al en 1994 describieron que los radicales libres ocasionan lesión de peroxidación de las células proteicas estructurales como la elastina, el colágeno, el ácido hialurónico, etc., con alteración de sus propiedades biofísicas y bioquímicas ${ }^{18}$. Promueven, además, enlaces cruzados mediados por grupos sulfhidrilos de algunos aminoácidos. Por acción de la proliferación de fibroblastos consecutiva a la actividad de los factores de crecimiento (mitógenos) y citocinas fibrogénicas producidos por los macrófagos, van instaurándose fibrosis, esclerosis, angiogénesis y células musculares lisas, como se observa en la arteriosclerosis y las enfermedades autoinmunitarias.

Además, se ha observado que los radicales libres, en particular el OH', atacan los ácidos grasos poliinsaturados y los fosfolípidos en los dobles enlaces carbono-carbono. Los ácidos grasos insaturados lesionados se convierten en radicales libres, con súbita restauración de sus dobles enlaces para formar un radical peroxi-ROO en presencia de $\mathrm{O}_{2}{ }^{19}$. De esa manera se forma una reacción en cadena, la lipoperoxidación $^{20}$, que termina cuando encuentran moléculas frenadoras. En el curso de estas reacciones se eliminan productos de degradación, como los malondialdehídos, que aumentan con la edad y sirven para medir el daño por peroxidación lipídica ${ }^{21}$. Este proceso determina una desorganización estructural; así, la membrana pierde su textura y sus funciones de información y la permeabilidad selectiva con entrada de calcio para activar las enzimas catabólicas.

Los radicales libres también son capaces de oxidar las lipoproteínas de baja densidad (LDL) 22 infiltradas en la membrana celular y entre las células endoteliales, sufriendo precipitación con tendencia a formar placas de ateroma en las arterias escleróticas ${ }^{23}$, además de inhibir las enzimas con grupos sulfhidrilos ${ }^{15,19}$, como la lisozima. Por ello, esta desempeña el papel de molécula barrendera, al igual que las vitaminas A, C, E, cisteína, glutatión, albúmina, etc. ${ }^{15,19}$. La lisozima es básica en la activación del gen supresor para convertirlo en antioncogén o gen supresor tumoral ${ }^{19}$.

Por último, los radicales libres, y en especial el radical hidroxilo, pueden lesionar el ADN de una célula somática por mutación puntual para determinar una lesión maligna ${ }^{19}$. Para el control normal de la proliferación de las células, se distinguen dos tipos de genes: a) los genes promotores o protooncogenes, encargados de promover la proliferación celular, son activados por la enzima ADN-polimerasa ${ }^{19} \mathrm{y}$, en caso patológico, también por los factores de crecimiento, y b) los genes supresores o reguladores de dicha proliferación, activados, como lo presumimos, por la lisozima ${ }^{19}$. El equilibrio entre estos dos tipos de genes mantiene una normal multiplicación celular.

Según el paradigma mitocondrial del cáncer ${ }^{24}$, las mutaciones en genes nucleares o mitocondriales que codifican componentes de la cadena transportadora de electrones pueden dar lugar a un incremento en la generación de especies de oxígeno reactivas (ROS, reactive oxygen species). Esto pasa cuando la cadena transportadora de electrones es inhibida parcialmente, lo que da lugar a acumulación de electrones que pueden ser capturados por el oxígeno y promueve la formación del radical superóxido. Este radical es rápidamente neutralizado por la enzima superóxido dismutasa, que da lugar al peróxido de hidrógeno, que pude difundir al núcleo y dañar el ADN, lo que contribuye a la inestabilidad genética. Un ejemplo de este proceso ha sido descrito en el cáncer de próstata, en el que las mutaciones en el $A D N$ se han relacionado con incrementos de la producción de radicales libres y progresión del tumor ${ }^{25}$. Aunque el campo es todavía emergente, hay muchas evidencias que apoyan la idea de que un incremento crónico de los radicales libres puede dar lugar a la transformación y contribuir a la progresión del cáncer amplificando la inestabilidad genómica.

\section{Incremento de los radicales libres en las células cancerígenas}

Estudios previos han indicado que las células cancerígenas pueden producir más radicales libres que las células norma$\operatorname{les}^{26}$. Una de las mayores dificultades de probar esta hipótesis surge de la ausencia de una "célula normal" comparable para usar como control. Algunos tipos celulares tienen incrementadas las actividades metabólicas respecto a otros tipos, y estas diferencias pueden fácilmente traducirse con incrementos en la formación de radicales libres. Por lo tanto, comparar una célula cancerígena que prolifera rápidamente con una célula quiescente normal puede llevar a diferencias en las concentraciones de radicales libres atribuibles a diferencias en sus actividades metabólicas, más que a la transformación oncogénica. Se requiere una línea celular control genéticamente comparable, preferiblemente una que replique algunos de los defectos genéti$\cos$ (no todos) que tiene la línea tumoral ${ }^{27}$.

Cuando hay un incremento de radicales libres, se genera un ambiente de hipoxia en la célula. La hipoxia es una característica prominente de tumores sólidos avanzados y el mayor determinante de la progresión maligna ${ }^{28,29}$. Aunque los mecanismos moleculares de la adaptación celular a la hipoxia están aún en debate, las ROS generadas en la mitocondria colaboran en este proceso ${ }^{30}$. Estos radicales determinan la activación de varios factores de transcripción, entre ellos el factor nuclear kappa B (NF-кB), que es un factor transcripcional redox identificado que puede dar lugar a la activación de genes tanto proinflamatorios como antiapoptóticos ${ }^{31,32}$

Se ha demostrado que las ROS tienen un papel dual en la señalización de la hipoxia. Por un lado, protegen a las célu- 
las cancerosas mediante la activación de $\mathrm{NF}-\kappa \mathrm{B}$, pero por otro la sobreproducción de ROS seguida de una depleción del glutatión reducido (GSH) mitocondrial sensibiliza las células cancerosas a la hipoxia ${ }^{33}$.

\section{Lisozima endógena y su función en la prevención del cáncer}

La lisozima es una enzima básica de carga eléctrica positi$\mathrm{va}^{34}$, constituida por una cadena polipeptídica de $129 \mathrm{ami}$ noácidos, ocho de los cuales son moléculas de cisteína que, por acción del radical $\mathrm{O}_{2}^{-}$forman cuatro puentes disulfuro de cistina que dan consistencia a la molécula enzimática y la mantienen plegada. Aquí los radicales libres actúan favorablemente. Para su síntesis la lisozima requiere ATP, siendo indispensables las vitaminas del complejo B. Aproximadamente el $40 \%$ de la cadena polipeptídica tiene forma de segmentos alfahelicoidales o secundaria, que dibuja una hendidura a un lado de la molécula y constituye el sitio activo de la enzima. Su estructura secundaria es mantenida por enlaces de $\mathrm{H}$ entre un grupo amida situado en cierta posición y un grupo carboxilo (CO) situado por arriba o por debajo. El $\mathrm{OH}^{\prime}$ rompe esos enlaces para formar agua, con lo que la molécula pierde su estructura secundaria con inhibición de la enzima.

\section{La lisozima como regulador o freno del crecimiento tumoral}

La lisozima actúa como regulador o "freno" de la replicación del ADN, o sea, como control de la multiplicación celular. Para ingresar en la célula, debe despolimerizar el mucopolisacárido que constituye los receptores existentes en la membrana. Esta es captada por receptores proteicos del citoplasma que por fosforilación translucen sus efectos reguladores sucesivamente hasta el gen p53 (supresor de proliferación y de tumores) del ADN del cromosoma 17 del núcleo de una célula somática ${ }^{19,34}$. Así se activa este gen, convirtiéndose en gen p53 salvaje, conocido como antioncogén o supresor tumoral. Este lleva la orden de controlar la replicación del ADN, es decir, de la multiplicación celular determinada por la ADN-polimerasa. Al disminuir la lisozima, sea por deficiente síntesis de ATP por cualquier causa como la hipovitaminosis B o por acción inhibidora de los radicales libres $\left(\mathrm{OH}^{\prime}\right)$, se salta el "freno" con predominio del protooncogén activado por la ADN-polimerasa y los factores de crecimiento ${ }^{19}$. En este caso puede suceder:

1. Dada la mayor actividad de la ADN-polimerasa y los factores de crecimiento por la falta o disminución del "freno", se va a generar una proliferación de células bien diferenciadas, normales, es decir, una hiperplasia del tejido afectado con características y producción de matriz intercelular (mucopolisacáridos) normales. Esto se debe a que el ARNm conserva la información del código genético. Así se produce el tumor benigno ${ }^{19}$.

2. Si en lugar de este fenómeno se opera una mutación puntual del protooncogén por acción del $\mathrm{OH}^{\prime}$ producido en exceso durante la inflamación crónica inespecífica o por acción de radiaciones ionizantes, este protooncogén se va a convertir en oncogén con deleción parcial de una base complementaria, el código genético se altera inmediatamente y el ARNm, con su mensaje genético alterado, va a estimular el ribosoma para que codifique una proteína intercelular anómala, la oncoproteína. La proliferación celular va a ser irregular, sin un patrón, descontrolada; las mitosis, más rápidas y las células, muy indiferenciadas o anaplásicas en la medida en que el proceso es más agresivo, activado, a su vez, por los factores de crecimiento (mitógenos) y citocinas fibrogénicas, determinantes de angiogénesis y fibrosis, es el tumor maligno ${ }^{9,19}$.

2. La tercera forma es una mezcla de las dos anteriores. La lesión comienza en forma de tumor benigno y en el transcurso de un tiempo variable el protooncogén sufre una mutación puntual para convertirse en tumor maligno, ya descrito, como sucede en la malignización del tumor mixto de parótida, el bocio, el papiloma laríngeo. Sin embargo, el tumor benigno no necesariamente sufre malignización. El oncogén producido por esta vía es lo que se denomina oncogénesis endógena o celular (c-onc), a diferencia de la exógena o viral ( $\mathrm{v}$-onc), que ocurre cuando al protooncogén se integra por mutagénesis insercional un virus $A D N$ oncógeno de carga eléctrica negativa, como el Papilomavirus (VPH) ${ }^{34}$, con mutación puntual de dicho gen del fibroblasto. Cuando el virus oncógeno no se integra al ADN nuclear, da lugar a la papilomatosis laríngea juvenil u otra lesión, y permanece latente en el soma del núcleo (con el nombre de episoma) sin determinar malignidad, aunque puede sufrirla en cualquier momento favorable. No obstante, para que dicha integración al $A D N$ se efectúe, se requiere que haya cierta predisposición dada por deficiencia de lisozima, porque la carga eléctrica positiva de esta produce inhibición, extracelular o en el citoplasma, del virus oncógeno de carga eléctrica negativa impidiéndole ingresar a la célula o integrarse al ADN nuclear, por lo que es el verdadero "guardián del genoma". Así se explica por qué los agentes cancerígenos parecen selectivos al afectar a unas personas y no a otras.

\section{Los antioxidantes de los alimentos y su papel en la prevención del cáncer}

Entre los principales componentes antioxidantes que aparecen en las frutas y hortalizas con valor antioxidante están los betacarotenos, las vitaminas A, C y E y el glutatión.

Los betacarotenos, carotenoides precursores de la vitamina $A$, son pigmentos vegetales que, una vez ingeridos, se transforman en el hígado y en el intestino delgado en vitamina $\mathrm{A}^{35}$. Es un componente antioxidante que favorece la prevención del cáncer, especialmente de pulmón, boca y estómago ${ }^{36,37}$. También se ha descrito que los betocarotenos previenen la aparición de enfermedades del corazón ${ }^{38}$. Además, como precursor de la vitamina $A$, resulta una manera adecuada de beneficiarse de las propiedades de esta vitamina, sin el riesgo de intoxicación que puede suponer una sobreingestión mediante suplementos. Un exceso de betacaroteno lleva a un estado de hipercarotenodermia, que se caracteriza por una coloración amarillenta de la piel, que 
es inocua y desaparece sin secuelas cuando se deja de ingerir alimentos ricos en betacarotenos. Entre los alimentos ricos en betacarotenos, se puede destacar los siguientes: la verdolaga, la zanahoria, las espinacas, el berro, la borraja, la acelga, la calabaza, el tomate, etc.

La vitamina A o retinol es una vitamina liposoluble; ayuda a la formación y el mantenimiento de dientes sanos y tejidos blandos y óseos, de las membranas mucosas y de la piel. La vitamina A es un nutriente esencial para el ser humano. Se conoce también como retinol o también como un ácido (ácido retinoico), ya que genera pigmentos necesarios para el funcionamiento de la retina. La vitamina A proviene de fuentes animales como pescados grasos, huevos, carnes, leche, queso y algunas vísceras. Sin embargo, todas estas fuentes, a excepción de la leche descremada enriquecida con vitamina $\mathrm{A}$, tienen un alto contenido de grasa saturada y colesterol ${ }^{39,40}$.

La vitamina $C$, o enantiómero $L$ del ácido ascórbico, es un nutriente esencial para los mamíferos. Se requiere esta vitamina para cierto número de reacciones metabólicas en todos los animales y las plantas, y se crea internamente en casi todos los organismos; los humanos son una notable excepción. Su deficiencia causa escorbuto en humanos, de ahí el adjetivo ascórbico que se da al ácido. También se usa ampliamente como aditivo alimentario. El farmacóforo de la vitamina $C$ es el ion ascorbato. En organismos vivos, el ascorbato es un antioxidante ${ }^{41}$ y cofactor en varias reacciones enzimáticas vitales ${ }^{42}$. Además de sus propiedades antioxidantes, esta vitamina es igualmente importante para la adecuada absorción de hierro, calcio o aminoácidos. Entre los principales alimentos ricos en vitamina $C$ se puede destacar los pimientos, una de las plantas con más cantidad, después de la acerola o el escaramujo. También son muy ricos en vitamina C los cítricos (naranjas, limones, pomelos, etc.). Desde su descubrimiento, la vitamina $\mathrm{C}$ ha sido considerada por algunos como la "panacea universal". Pese a que algunos defensores de la vitamina $C$ sostienen que, ingerida en frecuencia y dosis suficientemente alta y por largo tiempo ${ }^{43}$ puede prevenir e incluso curar una amplia gama de enfermedades comunes o letales, como el resfriado común y la enfermedad cardíaca, o incluso ayudar en el manejo del sida ${ }^{44}$, dichas afirmaciones no han sido demostradas en estudios humanos bien diseñados. El ácido deshidroascórbico, la principal forma de la vitamina $\mathrm{C}$ oxidada en el cuerpo, se ha relacionado con una reducción de los déficit neurológicos y la mortalidad derivada de accidentes cerebrovasculares, debido a su habilidad para atravesar la barrera hematoencefálica, mientras que la vitamina $\mathrm{C}$ o el L-ascorbato no logran atravesar dicha barrera ${ }^{45}$. En un estudio publicado por Proceedings of the National Academy of Sciences en 2001, los autores concluyeron que "una estrategia farmacológica de incrementar los niveles cerebrales de ascorbato en accidentes cerebrovasculares tiene el potencial enorme para representar la traducción oportuna de investigación básica en una terapia relevante para accidentes cerebrovasculares en humanos". En enero de 2007, la Food and Drug Administration (FDA) aprobó un ensayo de toxicidad de fase I para determinar dosis seguras de vitamina $C$ intravenosa como posible tratamiento del cáncer para quienes se han agotado otros tratamientos y opciones convencionales. En febrero de 2007, un estudio no controlado de 39 pacientes con cáncer termi- nal mostró que, en cuestionarios subjetivos, los pacientes declararon una mejoría en salud, síntomas del cáncer y funciones diarias después de la administración intravenosa de altas dosis de vitamina $C^{46}$. Los autores concluyeron que, "aunque existe aún la controversia respecto a los efectos anticancerosos de la vitamina $C$, su uso se considera una terapia segura y efectiva para mejorar la calidad de vida de pacientes con cáncer terminal". En agosto de 2008, un artículo publicado en Proceedings of the National Academy of Sciences por Levine et al, del Instituto Nacional de Diabetes y Enfermedades del Riñón, encontraron que la inyección directa de altas dosis de vitamina $\mathrm{C}$ reduce el peso y el crecimiento del tumor en un $50 \%$ en modelos de ratones con cáncer de ovario, cerebro y pancreático.

La vitamina E protege las membranas celulares de la oxidación mediante la protección de sus ácidos grasos insaturados. Una falta de esta vitamina parece producir cambios degenerativos en las células de algunos tejidos como las de los músculos y el corazón. Las personas diagnosticadas de fibrosis quística, los sujetos operados a los que se ha extirpado parte o todo el intestino o el estómago y los que tienen disminuida la capacidad de absorción de grasas (como en la enfermedad de Crohn) necesitan un suplemento de vitamina $\mathrm{E}$. Las personas que no pueden absorber grasas suelen tener una diarrea crónica ${ }^{47}$. Las verduras y hortalizas de color verde, así como los vegetales ricos en aceite, son las que poseen más cantidad de esta vitamina; por ejemplo, la verdolaga, los espárragos, la lechuga, los guisantes, las nueces, el germen de trigo o las semillas de girasol, que son las que tienen el contenido más alto ${ }^{48}$.

Por último, el glutatión (GSH), que se analiza con más profundidad más adelante, es otro componente con propiedades antioxidantes, que ayuda a eliminar los radicales libres, responsables de la aparición de muchas enfermedades, entre las cuales se encuentra el cáncer ${ }^{49}$. Este elemento, que aparece con la mayor cantidad en el brócoli, se encuentra fundamentalmente en la piel, por lo que deberemos comerlo crudo en ensalada ${ }^{50}$. Otros alimentos ricos en este componente son: el ajo, la patata, las espinacas, el maíz o la verdolaga. Además de esta propiedad, otros autores han destacado su capacidad para disminuir la presión arterial, favorecer el buen estado del hígado o prevenir eccemas ${ }^{51}$.

\section{El glutatión: uno de los principales antioxidantes de la célula y posible tratamiento contra el cáncer}

El glutatión es el tiol de bajo peso molecular más abundante en la célula, en concentraciones del orden milimolar, con gran eficacia estructural, y participa activamente en numerosos procesos de desintoxicación. Se trata de un tripéptido constituido por los aminoácidos glutamato y glicina, responsables de su destino metabólico, y la cisteína donde su grupo sulfhidrilo $(-\mathrm{SH})$, gracias a su potencial reductor, determina sus funciones metabólicas ${ }^{52}$.

\section{Síntesis de glutatión}

El GSH se sintetiza en todas las células de los mamíferos, pero los principales órganos encargados de la homeostasis 
del GSH son el hígado, el pulmón y el riñón. Su biosíntesis es el resultado del acoplamiento secuencial de dos reacciones enzimáticas dependientes de ATP, catalizadas por las enzimas gammaglutamilcisteína sintetasa $(\gamma$-GCS) y la GSH sintetasa $(\mathrm{GS})^{53}$.

El primer paso en la síntesis del GSH es la unión del glutamato y la cisteína a través del grupo gammacarboxilo del glutamato que, a diferencia del clásico enlace peptídico mediante el grupo alfacarboxilo, le transfiere resistencia a la hidrólisis por peptidasas. La única peptidasa capaz de hidrolizar el GSH es la gammaglutamiltranspeptidasa, enzima encargada de su transporte y presente en la superficie externa de ciertos tipos celulares. Esta reacción catalizada por la $\gamma$-GCS es la etapa limitante de la síntesis de GSH. La enzima requiere de $\mathrm{Mg}^{2+}$ y $\mathrm{Mn}^{2+}$ para su actividad, presenta especificidad hacia el glutamato y es inhibida por concentraciones fisiológicas de GSH, al competir por el sitio de unión al glutamato y por la disponibilidad de su precursor, la cisteína. La actividad de la $\gamma$-GCS puede ser inhibida específicamente y de forma irreversible por la butionina Lsulfoximina ${ }^{54}$. Finalmente, la síntesis se completa con la unión de glicina al dipéptido gammaglutamilcisteína a través de la enzima GSH sintetasa, que no es retroinhibida por el GSH. La glicina, como aminoácido terminal, es básica en la especificidad estructural de las enzimas dependientes de GSH y confiere protección contra la degradación intracelular producida por la gammaglutamilciclotranferasa ${ }^{55}$.

\section{Funciones del glutatión}

La concentración intracelular de GSH es un indicador muy sensible de la funcionalidad y la viabilidad celular. De hecho, la aparición de diferentes enfermedades se ha visto acompañada de una disminución de $\mathrm{GSH}^{56}$.

El GSH es una fuente importante de almacenamiento de cisteína. La cisteína en plasma es rápidamente autooxidada a cistina, fenómeno que implica una marcada toxicidad. La disminución de este efecto nocivo se consigue controlando la cantidad de cisteína libre o mediante el almacenamiento de esta en forma de GSH, cuyo grupo-SH es menos lábil que el de la cisteína libre ${ }^{57}$. De manera que, cuando el GSH es hidrolizado extracelularmente, se recupera la cisteína.

La desintoxicación de xenobióticos o sus metabolitos es una de las principales funciones del GSH. Estos compuestos electrófilos se conjugan con el GSH, tanto de manera espontánea como catalizada por la enzima glutatión S-transferasa (GST), dando lugar a mercapturatos que posteriormente serán eliminados.

El GSH participa también en la reducción de peróxidos de hidrógeno $\left(\mathrm{H}_{2} \mathrm{O}_{2}\right)$ y peróxidos orgánicos. Si el peróxido de hidrógeno no es reducido a agua, en presencia de ciertos metales de transición $\left(\mathrm{Fe}^{3+}, \mathrm{Cu}^{2+}\right)$, puede dar lugar, a través de la reacción de Haber-Weiss, a la formación del radical hidroxilo $(\mathrm{OH}$.), altamente reactivo y causa de la formación de peróxidos lipídicos. La GSH peroxidasa dependiente de selenio cataliza la reducción del peróxido de hidrógeno a agua utilizando el GSH como cofactor, dando lugar a la formación de la especie oxidada de glutatión (GSSG). En presencia de NADPH, el GSSG es reducido de nuevo por la GSH reductasa, con lo que se establece el denominado ciclo redox del GSH.
El GSH confiere integridad de grupos tioles, mantenimiendo la cantidad de tioles esenciales en proteínas, con lo que previene su oxidación, o reduciendo uniones disulfuros inducidas por el estrés oxidativo.

También participa en la conjugación con compuestos endógenos, como los intermediarios del metabolismo de prostaglandinas, leucotrienos y varias hormonas, y en la reducción de los ribonucleótidos a desoxirribonucleótidos.

\section{Glutatión mitocondrial}

El GSH se sintetiza en el citosol celular y su disponibilidad en los diferentes compartimentos celulares está determinada por complejas interacciones entre su utilización, su transporte, su síntesis y la tasa de reducción del GSSG a $\mathrm{GSH}^{58}$. El glutatión mitocondrial (GSHm) constituye un 10$15 \%$ del total celular y se encuentra en una concentración similar a la del citosol, de 9-12 $\mathrm{mM}^{59}$.

Con base en las conclusiones de varios estudios ${ }^{31,32}$, en los que se describe que la mitocondria es la principal fuente de radicales libres durante la hipoxia, se puede especular que la mitocondria es un lugar de sobreproducción de radicales libres en las células cancerígenas. En línea con esta posibilidad, el GSH y otros miméticos como pueden ser la S-adenosil-metionina (precursor del GSH) o el MnTBAP que reemplaza la manganeso-superóxido dismutasa, protegen las células contra la sobreproducción de radicales libres.

Por un lado, la hipoxia severa puede servir para tratar las células cancerígenas y eliminarlas; sin embargo, por otro, la hipoxia puede causar mutaciones genéticas en células normales y generar un proceso canceroso.

\section{Suplementación mediante la dieta}

La suplementación de GSH por vía oral es controvertida, ya que varias investigaciones indican que el GSH por vía oral no se absorbe bien en el tracto gastrointestinal. En un estudio de administración oral aguda de altas dosis de GSH (3 g), Witschi et al concluyeron que "no es posible aumentar la circulación de glutatión en un grado clínicamente beneficioso con la administración oral de una dosis única de $3 \mathrm{~g}$ de glutatión"60.

Sin embargo, las concentraciones de GSH plasmáticas y hepáticas pueden incrementarse con administración oral de $\mathrm{S}$-adenosil-metionina (SAM) ${ }^{61-63}$. Los precursores de GSH ricos en cisteína incluyen $\mathrm{N}$-acetilcisteína $(\mathrm{NAC})^{64}$ y proteína del suero sin desnaturalizar ${ }^{65-68}$, y se ha demostrado que estos suplementos aumentan el contenido de GSH de la célula. La NAC está disponible como medicamento y como suplemento genérico. También se ha demostrado que el ácido alfalipoico restaura el GSH intracelular ${ }^{69,70}$. La melatonina se ha relacionado con una estimulación de una enzima relacionada, la glutatión peroxidasa ${ }^{71}$. En modelos animales, la silimarina o cardo de leche también ha mostrado capacidad para reponer glutatión. La NAC, fármaco usado en la lucha contra las drogas, y la cisteína han mostrado en modelos animales eficacia en aumentar los valores de GSH ${ }^{72,73}$. No se han encontrado estudios realizados en humanos.

El GSH es un componente intracelular fuertemente regulado y limitado en su producción debido a la inhibición de retroalimentación negativa de su propia síntesis a través de 
la enzima gammaglutamilcisteína sintetasa, con lo que se reduce en gran medida el riesgo de sobredosis. El aumento de GSH es una estrategia para hacer frente a los estados de carenciales de esta, como en casos de estrés oxidativo, inmunodeficiencia y sobrecarga de xenobióticos (el GSH desempeña un papel en la desintoxicación de los xenobióticos en cuestión). Los estados de deficiencia de GSH incluyen, entre otros: $\mathrm{VIH} /$ sida, la química y la hepatitis infecciosa, cáncer de próstata y otros tipos de cáncer, cataratas, Alzheimer, Parkinson, enfermedad pulmonar obstructiva crónica, asma, envenenamiento por radiación, estados de desnutrición, estrés físico extremo y envejecimiento, y se ha asociado con respuesta inmunitaria subóptima. Muchas enfermedades clínicas están relacionadas con el estrés oxidativo y se detallan en numerosas referencias médicas ${ }^{74}$.

La escasez de GSH también está fuertemente implicada en el desgaste y el balance negativo de nitrógeno, particularmente en procesos cancerosos, sida, sepsis, traumatismos, quemaduras e incluso sobreentrenamiento deportivo. El suplemento con GSH puede oponerse a este proceso y en el sida, por ejemplo, puede dar como resultado mejores tasas de supervivencia ${ }^{75}$.

Tener adecuadas concentraciones de GSH en el organismo puede ayudar a mantener, principalmente, un equilibrio óptimo en la eliminación de radicales libres (efecto antioxidante), así como auxiliar para la desintoxicación de las células del hígado debido a que dicha proteína tiene una excelente capacidad para reaccionar con sustancias tóxicas (acetaminofeno, cobre, cadmio y paracetamol) y favorecer su eliminación. El GSH es un ingrediente clave para potenciar al máximo la actividad antioxidante de las vitaminas $C$ y E, acetilcisteína, ácido alipoico y trazas de selenio. El GSH y el selenio tienen la función de regenerar la vitamina $C$ gastada. Asimismo, el GSH, el selenio y la vitamina $C$ juntos regeneran la vitamina $\mathrm{E}$. Esta relación sinérgica mantiene las defensas antioxidantes de la célula intactas todo el tiempo. Cantidades adecuadas de GSH junto con los otros antioxidantes en nuestros cuerpos son esenciales para tener un sistema de defensa efectivo contra los radicales libres $^{55}$.

Los alimentos ricos en azufre contienen aminoácidos que pueden ayudar a aumentar el GSH. Algunas de las fuentes de alimentos y suplementos dietéticos que ayudan a aumentar el GSH natural son:

$N$-acetilcisteína (NAC). Se deriva del aminoácido L-cisteína y actúa como precursor del GSH. La NAC se metaboliza rápidamente en GSH, una vez que entra en el cuerpo.

Cardo mariano (silimarina). Pese a que solamente se ha estudiado su eficacia en modelos animales, la silimarina (el compuesto activo del cardo mariano) puede ser un potente antioxidante y un desintoxicante natural del hígado, al que podría proteger de muchas toxinas, tales como el tetracloruro de carbono o el alcohol.

Ácido alfalipoico. Fabricado de forma natural en las células del cuerpo como un subproducto de la liberación de energía, el ácido alfalipoico puede aumentar el GSH intracelular y es un antioxidante natural con capacidad de captación de radicales libres. Asimismo, en modelos celulares se ha mostrado capaz de regenerar los antioxidantes como las vitaminas $C$ oxidada y $E$ y ayuda a hacerlos más potentes.
Alimentos que aumentan el GSH. El espárrago es una fuente principal de GSH. Los alimentos como brócoli, aguacate y espinaca aumentan el GSH. Los huevos crudos, el ajo fresco y las carnes sin procesar contienen gran concentración de azufre y aminoácidos y ayudan a mantener valores óptimos de $\mathrm{GSH}^{84}$.

Proteína aislada de suero sin desnaturalizar. La proteína del suero contiene proteínas como la alfalactoalbúmina, rica en azufre que contienen los aminoácidos. La calefacción o pasteurización destruye los enlaces disulfuro que dan a estas proteínas su bioactividad. La proteína de suero sin desnaturalizar es un producto sin calefacción que conserva bioactivos aminoácidos como la cistina. Se ha demostrado en numerosos estudios científicos en modelos animales y ensayos clínicos que optimiza la concentración de $\mathrm{GSH}^{85,86}$. Curcumina (cúrcuma). El tratamiento de las células del cerebro llamadas astrocitos con la curcumina del curry indio (cúrcuma) aumenta la expresión de la glutatión S-transferasa y protege las neuronas expuestas a estrés oxidativo ${ }^{87}$. Globo raíz de flores. Saponinas Changkil (CKS) aisladas de las raíces de la medicina herbal china, Platycodon grandiflorum A. DC (Campanulaceae), comúnmente llamada flor de globo raíz o Jie Geng, se han encontrado que aumenta el GSH intracelular y reduce significativamente el contenido de daño oxidativo a las células del hígado y la muerte celular y minimiza la peroxidación lipídica en estudios in vitro ${ }^{88}$.

Selenio. El selenio es un cofactor de la enzima glutatión peroxidasa. Los suplementos de selenio se han hecho populares debido a que algunos estudios en animales indican que puede ser útil en la disminución del riesgo de ciertos tipos de cáncer, y en la función del sistema inmunitario y la glándula tiroides. Sin embargo, demasiado selenio puede causar algunos efectos tóxicos y malestar gastrointestinal ${ }^{89,90}$.

\section{Relación entre el glutatión y el cáncer}

El GSH ha mostrado resultados positivos en varios estudios preliminares sobre su capacidad para alterar la concentración de ROS, lo que podría tener repercusiones en la reducción de los tipos de cáncer ${ }^{76,77}$.

Sin embargo, al conferir resistencia a varios fármacos quimioterápicos, las concentraciones elevadas de GSH en las células tumorales son capaces de protegerlas en médula ósea, mamas, colon, laringe y pulmones ${ }^{78}$.

\section{Conclusiones}

El daño causado por los radicales libres y el estrés oxidativo puede dar lugar a varios tipos de cáncer. Los antioxidantes interactúan con los radicales libres y los estabilizan, con lo que pueden evitar parte del daño que estos podrían causar. Es importante mantener una buena alimentación y fomentar el consumo de frutas y hortalizas ricas en componentes antioxidantes como el GSH, los betacarotenos y las vitaminas $C$ y $E$ para la prevención y el tratamiento del cáncer.

El GSH tiene un gran potencial reductor y es el antioxidante por excelencia de la célula, y se ha demostrado en 
varios estudios experimentales su efecto beneficioso para la reducción de varios tipos de cáncer ${ }^{78}$. La concentración de GSH se puede incrementar principalmente mediante tratamiento con S-adenosil-metionina o $\mathrm{NAC}^{76}$.

\section{Bibliografía}

1. Adachi M, Zhang Y, Zhao X, Minami T, Kawamura R, Hinoda Y, et al. Clin Cancer Res. 2004;10:3853-62.

2. Anand $P$, Kunnumakkara $A B$, Kunnumakara $A B$, et al. Cancer is a preventable disease that requires major lifestyle changes. Pharm Res. 2008;25:2097-116.

3. Kinzler KW, Vogelstein B. The genetic basis of human cancer 2. ${ }^{\mathrm{a}}$ ed. New York: McGraw-Hill; 2002. p. 5.

4. Irigaray P, Newby JA, Clapp R, et al. Lifestyle-related factors and environmental agents causing cancer: an overview. Biomed Pharmacother. 2007;61:640-58.

5. Matill HA. Antioxidants. Annu Rev Biochem. 1947;16:177-92.

6. Roche $E$, Romero D. Estrés oxidativo y degradación de proteínas. Med Clin (Barc). 1994;103:189-96.

7. Cotran RS, et al. Patología estructural y funcional. 5. ${ }^{\mathrm{a}}$ ed. McGraw-Hill/Interamericana.

8. Martins MA, et al. Interaction between inflammation and systemic haematologic effect of PAF-acether in the rat. L Pharmacol. 1989;36:333-60.

9. Jiménez S. Antioxidantes y RL en el tabaquismo. Buenos Aires: Solo-Mujeres; 2003.

10. Knight J. Free radicals: their history and current status in aging and disease. Ann Clin Lab Sci. 28:331-46.

11. Coulter I, Hardy M, Morton S, Hilton L, Tu W, Valentine D, et al. Antioxidants vitamin $\mathrm{C}$ and vitamin $\mathrm{E}$ for the prevention and treatment of cancer. J Gen Intern Med. 2007;21:735-44.

12. Hirota K, Murata M, Sachi Y, Nakamura H, Takeuchi J, Mori K, et al. Distinct roles of thioredoxin in the cytoplasm and in the nucleus. A two-step mechanism of redox regulation of transcription factor NF-кB. J Biol Chem. 1999;274:27891-7.

13. Perez-Galan P, Roue G, Villamar N, Campo E, Colomer D. The proteasome inhibitor bortezomib induces apoptosis in mantlecell lymphoma through generation of ROS and Noxa activation independent of p53 status. Blood. 2006;107:257-64.

14. Atalla S, Toledo-Pereya LH, McKenzie GH, Cederna JP. Influence of oxygen-derived free scavengers. Transplantation. 1985;40:584-90.

15. McWen BS. Protective and damaging effects of stress mediators. N Engl J Med.

16. De Ross AJ, et al. Cancer incident among Glyphosate-Exposed Pesticida Applicators in the Agricultural Health Study. Environ Health Perspect. 2005;113:49-54.

17. Shimosawa T. [Increasing oxidative stress in aging]. Nippon Rinsho. 2005;63:994-9.

18. Southern PA, Powis G. Medicine. II. Involvement in human disease. Mayo Clin Proc. 1994;63:390-404.

19. Altamar J. Herbicidas y Malf. Congén. en el Meta, Colombia. Actividad Patogénica de los RL. Orinoquia, Villavicencio, Colombia, 2002; 6: 9-35.

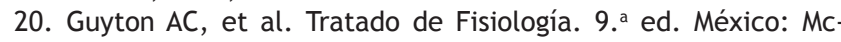
Graw-Hill/Interamericana; 1997.

21. Villa Pérez M. RL de $\mathrm{O}_{2}$ y la enfermedad. Conferencia en la VI Reunión del Grupo Español de RL. Cádiz, 26-28 de Junio de 2002.

22. De Ross AJ, et al. Cancer incidente among Glyphosate-Exposed Pesticida Applicators in the Agricultural Health Study. Environ Health Perspect. 2005;113:49-54.

23. Hallivell B. Current review. Free reactive oxygen species human disease, a critical evaluation with special reference to aterosclerosis. B Exp Path. 1995;70:737-57.
24. Wallace DC. A mitochondrial paradigm of metabolic and degenerative diseases, aging, and cancer: a dawn for evolutionary medicine. Annu Rev Genet. 2005;39:359-407.

25. Petros JA, Baumann AK, Ruiz-Pesini E, Amin MB, Sun CQ, Hall J, et al. Proc Natl Acad Sci U S A. 2005;102:719-24.

26. Szatrowski TP, Nathan CF. Cancer Res. 1991;51:794-8.

27. Schumacker P. Reactive oxygen species in cancer cells: Live by the sword, die by the sword. Cancer Cell. 2006;10:175-6.

28. Bertout JA, Patel SA, Simon MC. The impact of $\mathrm{O}_{2}$ availability on human cancer. Nat Rev Cancer. 2008;8:967-75.

29. Rankin EB, Giaccia AJ. The role of hypoxia-inducible factors in tumorogenesis. Cell Death Differ. 2008;15:678-85.

30. Denko NC. Hypoxia, HIF1 and glucosa metabolism in the solid tumor. Nat Rev Cancer. 2008;8:705-13.

31. Guzy RD, Hoyos B, Robin E, et al. Mitochondrial complex III is required for hypoxia-induced ROS production and cellular oxygen sensing. Cell Metab. 2005;1:401-8.

32. Lluis JM, Buricchi F, Chiarugi P, Morales A, Fernandez-Checa JC. Dual role of mitochondrial reactive oxygen species in hypoxia signaling: activation of nuclear factor-kappa B via c-SRC and oxidant-dependent cell death. Cancer Res. 2007;67: 7368-77.

33. Han D, Hanawa N, Saberi B, Kaplowitz N. Mechanisms of liver injury. Role of glutathione redox status in liver injury. Am J Physiol Gastrointest Liver Physiol. 2006;291:G1-7.

34. Altamar J. The role of lysozime on etiopathogenesis and treatment on juvenile laryngeal papillomatosis. Otolaryngol Torino. 1998;44:17-20.

35. Bjelakovic G, Gluud LL, Nikolova D, Bjelakovic M, Nagorni A, Gluud C. Antioxidant supplements for liver diseases. Cochrane Database Syst Rev. 2011;(3):CD007749.

36. Cranganu A, Camporeale J. Nutrition aspects of lung cancer. Nutr Clin Pract. 2009;24:688-700.

37. Persson C, Sasazuki S, Inoue M, Kurahashi N, Iwasaki M, Miura $\mathrm{T}$, et al. Plasma levels of carotenoids, retinol and tocopherol and the risk of gastric cancer in Japan: a nested case-control study. Carcinogenesis. 2008;29:1042-8.

38. Charniot JC, Vignat N, Albertini JP, Bogdanova V, Zerhouni K, Monsuez JJ, et al. Oxidative stress in patients with acute heart failure. Rejuvenation Res. 2008;11:393-8.

39. Eledrisi MS, McKinney K, Shanti MS. Vitamin A toxicity [citado 2 Sep 2009]. Disponible en: http://emedicine.medscape.com/ article/126104-overview

40. Litwack G. Vitamin A. Vitamins and hormones. Elsevier; 2007.

41. Wilson LG. The clinical definition of scurvy and the discovery of vitamin C. J Hist Med. 1975;40-60.

42. Challem JJ, Taylor EW. Retroviruses, ascorbate, and mutations, in the evolution of Homo sapiens. Free Radical Biology and Medicine. 1998;25:130-2.

43. Bánhegyi G, Braun L, Csala M, Puskás F, Mandl J. Ascorbate metabolism and its regulation in animals. Free Radical Biology and Medicine. 1997;23:793-803.

44. Villamor E, Koulinska IN, Aboud S, Murrin C, Bosch RJ, Manji KP, et al. Effect of vitamin supplements on HIV shedding in breast milk. Am J Clin Nutr. 2010;92:881-6.

45. Huang J, Agus DB, Winfree CJ, Kiss S, Mack WJ, McTaggart RA, et al. Dehydroascorbic acid, a blood-brain barrier transportable form of vitamin C, mediates potent cerebroprotection in experimental stroke. Proc Natl Acad Sci. 2001;98:11720-4.

46. Ichim TE, Minev B, Braciak T, Luna B, Hunninghake R, Mikirova $\mathrm{NA}$, et al. Intravenous ascorbic acid to prevent and treat cancer-associated sepsis? J Transl Med. 2011;9:25.

47. Institute of Medicine, Food and Nutrition board. Dietary Reference Intakes: Vitamin C, Vitamin E, Selenium, and Carotenoids. Washington: National Academy Press; 2000.

48. Rosenberg H, Feldzamen AN. The book of vitamin therapy. New York: Berkley; 1974 
49. Balendiran GK, Dabur R, Fraser D. The role of glutathione in cancer. Cell Biochem Funct. 2004;22:343-52.

50. Pompella A, Visvikis A, Paolicchi A, De Tata V, Casini AF. The changing faces of glutathione, a cellular protagonist. Biochem Pharmacol. 2003;66:1499-503.

51. Bounous G, Gold P. The biological activity of undenatured dietary whey proteins: role of glutathione. Clin Invest Med. 1991;14:296-309.

52. Meister A, Yaniguchi N, Higashi T, Sakamoto Y. Glutathione centennial. San Diego: Academic Press; 1989. p. 3-21.

53. Griffith $\mathrm{O}$, Meister A. Potent and specific inhibition of glutathione synthesis by buthionine sulfoximine. J Biol Chem. 1979;254:7558-60.

54. Meister A. Glutathione metabolism. Methods Enzymol Rev. 1995;251:3-7.

55. Wu G, Fang YZ, Yang S, Lupton JR, Turner ND. Glutathione metabolism and its implications for health. J Nutr. 2004;134:489. 92.

56. Cooper A. Biochemistry of sulfur-containing amino acids. Annu Rev Biochem. 1983;52:187-222.

57. Wahllander A, Soboll A, Sies H. Hepatic mitochondrial and cytosolic glutathione content and the subcellular distribution of GSH-S- transferases. FEBS Lett. 1975;97:138-40.

58. García-Ruiz C, Morales A, Colell A, Ballesta A, Rodés J, Kaplowitz N, et al. Effect of chronic ethanol feeding on glutathione and functional integrity of mitochondria in periportal and perivenous rat hepatocytes. J Clin Invest. 1994;94:193-201.

59. Sa G, Das T, Moon C, et al. GD3, an overexpressed tumor-derived ganglioside, mediates apoptosis of activated but not resting T cells. Cancer Res. 2009;69:3095-104.

60. Witschi A, Reddy S, Stofer B, Lauterburg BH. The systemic availability of oral glutathione. Eur J Clin Pharmacol. 1992;43:6679.

61. Liber CS. S-Adenosyl-L-methionine: its role in the treatment of liver disorders. Am J Clin Nutr. 2002;76:S1183-7.

62. Vendemiale G, Altomare E, Trizio T, Le Grazie C, Di Padova C, Salerno MT, et al. Effects of oral S-adenosyl-L-methionine on hepatic glutathione in patients with liver disease. Scand J Gastroenterol. 1989;24:407-15.

63. Loguercio C, Nardi G, Argenzio F, Aurilio C, Petrone E, Grella A et al. Effect of S-adenosyl-L-methionine administration on red blood cell cysteine and glutathione levels in alcoholic patients with and without liver disease. Alcohol Alcohol. 1994;29:597 604

64. Gross CL, Innace JK, Hovatter RC, Meier HL, Smith WJ. Biochemical manipulation of intracellular glutathione levels influences cytotoxicity to isolated human lymphocytes by sulfur mus tard. Cell Biol. 1993;9:259-67.

65. Moreno YF, Sgarbieri VC, Da Silva MN, Toro AA, Vilela MM. Features of whey protein concentrate supplementation in children with rapidly progressive HIV infection. J Trop Pediatr 2006;52:34-8.

66. Grey V, Mohammed SR, Smountas AA, Bahlool R, Lands LC. Improved glutathione status in young adult patients with cystic fibrosis supplemented with whey protein. J Cyst Fibros. 2003;2:195-8

67. Micke P, Beeh KM, Buhl R. Effects of long-term supplementation with whey proteins on plasma glutathione levels of HIVinfected patients. Eur J Nutr. 2002;41:12-8.

68. Bounous G, Baruchel S, Falutz J, Gold P. Whey proteins as a food supplement in HIV-seropositive individuals. Clin Invest Med. 1993;16:204-9.

69. Shay KP, Moreau RF, Smith EJ, Smith AR, Hagen TM. Alpha-lipoic acid as a dietary supplement: Molecular mechanisms and therapeutic potential. Biochim Biophys Acta. 2009;1790:1149-60.
70. Busse E, Zimmer G, Schopohl B, Kornhuber B. Influence of alpha-lipoic acid on intracellular glutathione in vitro and in vivo. Arzneimittelforschung. 1992;42:829-31.

71. Barlow-Walden LR, Reiter RJ, Abe M, Pablos M, Menendez-Pelaez A, Chen LD, et al. Melatonin stimulates brain glutathione peroxidase activity. Neurochem Int. 1995;26:497-502.

72. Nencini C, Giorgi G, Micheli L. Protective effect of silymarin on oxidative stress in rat brain. Phytomedicine. 2007;14:129-35.

73. Valenzuela A, Aspillaga M, Vial S, Guerra R. Selectivity of silymarin on the increase of the glutathione content in different tissues of the rat. Planta Med. 1989;55:420-2.

74. Immunocal Powder Sachets patient advice including side effects.

75. Herzenberg LA, De Rosa SC, Dubs JG, Roederer M, Anderson MT, Ela SW, et al. Glutathione deficiency is associated with impaired survival in HIV disease. Proc Natl Acad Sci U S A. 1997;94:1967-72.

76. Han $\mathrm{YH}$, Park WH. The effects of $\mathrm{N}$-acetyl cysteine, buthionine sulfoximine, diethyldithiocarbamate or 3-amino-1,2,4-triazole on antimycin A-treated Calu-6 lung cells in relation to cell growth, reactive oxygen species and glutathione. Oncol Rep. 2009;22:385-91.

77. Chow HH, Hakim IA. Modulation of human glutathione s-transferases by polyphenone intervention. Cancer Epidemiol Biomarkers Prev. 2007;16:1662-6.

78. Balendiran GK, Dabur R, Fraser D. The role of glutathione in cancer. Cell Biochem Funct. 2004;22:343-52.

79. Jomova K, Jenisova Z, Feszterova M, Baros S, Liska J, Hudecova $\mathrm{D}$, et al. Arsenic: toxicity, oxidative stress and human disease. J Appl Toxicol. 2011;31:95-107.

80. Ambrozova G, Pekarova M, Lojek A. The effect of lipid peroxidation products on reactive oxygen species formation and nitric oxide production in lipopolysaccharide-stimulated RAW 264.7 macrophages. Toxicol In Vitro. 2011;25:145-52.

81. Rammal H, Bouayed J, Younos C, Soulimani R. Evidence that oxidative stress is linked to anxiety-related behaviour in mice. Brain Behav Immun. 2008;22:1156-9.

82. Giovannucci E, Ascherio A, Rimm EB, Stampfer MJ, Colditz GA, Willett WC. Intake of carotenoids and retinol in relation to risk of prostate cancer. J Natl Cancer Inst. 1995;87:1767-76.

83. Giovannucci E, Willett WC, Stampfer MJ, Liu Y, Rimm EB. A prospective study of tomato products, lycopene, and prostate cancer risk. J Natl Cancer Inst. 2002;94:391-6.

84. Woodside J, McCall D, McGartland C, Young I. Micronutrients: dietary intake v. supplement use. Proc Nutr Soc. 2005;64:54353.

85. Cao G, Prior R. Comparison of different analytical methods for assessing total antioxidant capacity of human serum. Clin Chem. 1998;44 (6 Pt 1):1309-15.

86. Marshall K. Therapeutic applications of whey protein. Altern Med Rev. 2004;9:136-56.

87. Pocernich CB, Bader Lange ML, Sultana R, Butterfield DA. Nutritional approaches to modulate oxidative stress in Alzheimer's disease. Curr Alzheimer Res. 2011;8:452-69.

88. Lee KJ, Choi CY, Chung YC, Kim YS, Ryu SY, Roh SH, et al. Protective effect of saponins derived from roots of Platycodon grandiflorum on tert-butyl hydroperoxide-induced oxidative hepatotoxicity. Toxicol Lett. 2004;147:271-82.

89. Banni M, Chouchene L, Said K, Kerkeni A, Messaoudi I. Mechanisms underlying the protective effect of zinc and selenium against cadmium-induced oxidative stress in zebrafish Danio rerio. Biometals. 2011.

90. Kim JH, Kim BW, Kwon HJ, Nam SW. Curative effect of selenium against indomethacin-induced gastric ulcers in rats. J Microbiol Biotechnol. 2011;21:400-4 